\title{
Corporate social responsibility practices, involvement and challenges among hotels establishments in China
}

$\mathrm{Fu}$, Wuping

Huaihua University, China (felicity.fu@qq.com)

Borbon, Noelah Mae D. $\measuredangle$

Lyceum of the Philippines University Batangas, Philippines (nmdborbon@lpubatangas.edu.ph)

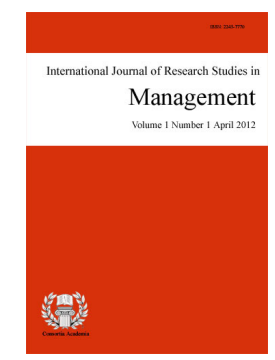

ISSN: $2243-7770$ Online ISSN: 2243-7789

OPEN ACCESS

\section{Abstract}

With the rapid growth of the economy, China's hotel industry developed rapidly in recent years. Corporate social responsibility has become a hot topic in academic and industrial circles, which has attracted wide attention from all walks of life. The purpose of this study is to explore the CSR practices of hotel establishments in China. This study utilized statistical quantitative analysis method to analyze the data collected. The respondents of the study are the 436 employees of hotel establishments directly involved in CSR initiatives, including front-line employees, grass-roots managers, middle managers and senior managers. The percentage and weighted mean value are used to analyze the various indicators of CSR practices and involvement on CSR initiatives. The results show that all respondents confirm that their hotels not only actively implement CSR practices in environmental, charitable, social engagement and ethical labor, but also in CSR projects, practices and activities in the environment, volunteering activities and goodwill. The respondents agree that their hotels attached great importance to environmental protection, formulating various CSR projects and activities to help the community, focusing on raising public safety awareness and environmental awareness, caring for employees and paying attention to the needs of them. Respondents also confirm that they were involved in CSR projects and activities between the hotel and the community, partners and customers, and maintain a harmonious relationship with the community.

Keywords: CSR, hotel employees, environmental, philanthropical, volunteering 


\section{Corporate social responsibility practices, involvement and challenges among hotels establishments in China}

\section{Introduction}

The hotel industry, as a highly related and radiating industry, plays an important role in protecting the environment, saving energy and sustainable development (Yao, 2012). However, the rapid development of economy inevitably caused serious pollution to the environment, leading to climate change and extreme weather. Therefore, the social responsibility of hotels plays an important role in standardizing hotel management behavior, improving hotel management environment and promoting hotel sustainable development (Li, 2012). Many star-rated hotels, especially international hotel groups, began to take the initiative to assume corporate social responsibility and disclose annual corporate social responsibility information. There is not a definite concept of CSR so far in the academic world. Scholars often define CSR according to the specific characteristics of each industry. It is of great theoretical and practical significance to gradually clarify and standardize the hotel environmental social responsibility reporting system for enhancing the competitiveness of enterprises and promoting the construction of environmental governance and accountability system (Tang, 2014).

With the increase of world population and the expansion of economic scale, the global environment is facing a severe test, and the pressure of rapidly developing economic activities on resources and environment is gradually deepening. Hunan's excessive dependence on material resources has not contained the deterioration of the ecological environment, which makes people realize the importance of protection of environment and fulfilling corporate social responsibility. With the development of globalization and broadcast of the perception of corporate social responsibility, corporate social responsibility issues are widely discussed both in and abroad the country. Corporate social responsibility is the heart and soul of modern corporations and is an important standard for corporations. It is an indispensable mechanism for both increased corporate accountability, profitability, and environmental sustainability (Borbon, 2019).

Corporate social responsibility (CSR) is mandated by the Chinese law. In compliance of the Company Law of China, the Chinese law encourages and requires all the business establishments to implement, participate and support any CSR in the operation of the business in the country, may it be local or international. This also prescribed in many other laws such as Labor Law, Environmental Protection Act, Product Reliability Law, Law on Protection of the Rights, and Interests of Consumers, etc. At present, tourism industry has made unprecedented development, becoming one of the most competitive pillar industries in the world (Zhang, 2015). With the development of business and tourism, the hotel industry, one of the three pillars of tourism industry, has also gained unprecedented development. Hotel industry is an important part of social and economic organization of China, which is usually regarded as the "image window" of a city.

This study focuses on CSR practices, involvement, and challenges in hotels establishments in China. These three points will be the foundation of a proposed CSR of this industry and to implement it. Moreover, this study explores the current situation and challenges of corporate social responsibility practices in hotel establishments through the perspective of employees' perception of corporate social responsibility in China and analyzes its perception of corporate social responsibility from the perspective of employees. It is helpful for managers of hotel establishments to strengthen the construction and development direction of corporate social responsibility for employees, and to provide referential suggestions for the internal management of corporate social responsibility and the healthy development of the industry in China through this study.

\subsection{Objectives of the Study}

This study aims to propose a framework of CSR commitment for five-star hotels in China. More specifically, 
Corporate social responsibility practices, involvement and challenges among hotels establishments in China

the study aims to answer the following objectives: (1) to determine the various practices of five-star hotels in terms of Environmental effort, Philanthropic Effort, Social Engagement and Ethical Labor; (2) to determine the level of involvement of the respondents in terms of environmental effort, volunteering, and goodwill; (3) to determine the internal and external challenges encountered by the five-star hotel. Furthermore, (4) test the relationship between the practices, involvement, and challenges of CSR. (5) Based on the results, this study proposed some recommendations for five-star hotels to better implement CSR.

\section{Methods}

Design and instruments - The researcher in this study uses the descriptive survey method and the method of statistical analysis. The instrument used is an adopted from the study of Borbon (2019) entitled: A Proposed Framework of Commitment for Hotel Industry in CALABARZON, Vizconde (2019) entitled: Sustainable Community-Based Development Framework for Golf Courses and Country Clubs in the Philippines and Borbon (2020) entitled: Corporate Social Responsibility Practices among DOT Accredited Hotel Establishments in CALABARZON. The researcher revised the questionnaire according to the actual situation of the development of hotel industry in China, where it was validated and run into a pilot testing to ensure the reliability of the instrument.

Participants - The respondents of the study are employees of hotel establishments from different cities of China. The researcher conducted the questionnaire survey online and administered the questionnaire to the target respondents. The researcher issued the questionnaire-on-Questionnaire Star Website (a special website for survey online) from November 15 till December 7 of 2020. A total number of 436 samples were collected in the end.

Data analysis - After gathered the data needed, personal encoding was successfully done by the researcher after gathering all the data. SPSS was used to interpret and analyze the data gathered. Weighted mean and rank are employed to analyze the CSR practices, involvement on CSR initiatives and challenges encountered in the hotel establishments. The researcher also utilized T-test and ANNOVA to analyze the significant difference on the responses when grouped according to profile and test the relationship among the variables.

\section{Results and discussion}

\section{Table 1}

Practices on corporate social responsibility of hotel establishments

\begin{tabular}{lccc}
\hline \multicolumn{1}{c}{ Indicators } & Weighted Mean & Verbal Interpretation & Rank \\
\hline 1. Environmental Effort & 3.41 & Often & 1 \\
2. Philanthropical Effort & 3.25 & Often & 4 \\
3. Social Engagement & 3.28 & Often & 3 \\
4. Ethical labor & 3.36 & Often & 2 \\
& 3.33 & Often & \\
\hline
\end{tabular}

Legend: $3.50-4.00=$ Always; $2.50-3.49=$ Often; $1.50-2.49=$ Sometimes; $1.00-1.49=$ Never

Table 1 presents the CSR practices of hotel establishments. The computed composite mean of 3.33 implies that the respondents have positive responses on the CSR practices of hotel establishments. As discussed on the table, hotel establishments highlight the importance of CSR practices. They do actively practice corporate social responsibility of the hotel establishment in China in terms of environmental aspect, philanthropical effort, social engagement, and ethical labor. The most frequently practiced CSR among hotel establishments is in relation to environmental effort (3.41) followed by ethical labor (3.36) and social engagement (3.28). The leased practiced CSR of hotel establishments is philanthropical effort (3.25).

Environmental effort is the most practiced CSR of hotel establishments (3.41). Environmental issue is highlighted for the problem of climate change and globe warming. Environmental problems have also become a major threat to human life and health. Tourism industry has a close relationship with environment, thus in terms 
of the content of environmental training, hotel managers should focus on topics that raise employees' ecological awareness rather than merely teaching employees how to operate environmentally friendly equipment. Policymakers and regulators may introduce incentive schemes (including tax incentives) or subsidies to firms that practice environmentally friendly activities or firms that take the initiative to minimize their environmental impact. With this incentive, firms may be encouraged to invest more actively in environmental activities (Tan, Habibullah, Tan, \& Choon, 2017).

Zhao (2018) suggests that environmental CSR practices of hotels include two categories: environmental practices on the material basis and environmental practices of management capacity. According to the study of Ouyang et al. (2019), hotels' environmental management practices are a result of their willingness to conform to the environmental expectations from investors, employees, and local communities. Chen (2019) affirms that stakeholders should promote green hotel policies to independent operators to achieve a higher brand value with lower carbon emissions and to adopt greater use of business intelligence to assist the decision-making of hotel operators in conformity with the United Nations (UN) Sustainable Development Goals (SDGs). The study suggests an alternative approach to improving environmental performance while considering economic branding value with a lower cost than that of green certification. These environmental CSR practices of hotels can improve the awareness of environmental protection of owners and employees of hotels, promote them to actively participate in environmental protection activities, but also increase the economic benefits for the hotel, reduce the loss of hotel staff, increase the sense of belonging of employees and customers.

\section{Table 2}

Involvement on CSR initiatives of hotel establishments

\begin{tabular}{|c|c|c|c|}
\hline Indicators & Weighted Mean & Verbal Interpretation & Rank \\
\hline 1. Environmental Effort & 3.32 & Involved & 1 \\
\hline 2. Volunteering & 3.24 & Involved & 2.5 \\
\hline 3. Goodwill & 3.24 & Involved & 2.5 \\
\hline Composite Mean & 3.27 & Involved & \\
\hline
\end{tabular}

Legend: $3.50-4.00=$ Highly Involved ; $2.50-3.00=$ Involved; $1.50-2.49=$ Slightly Involved; $1.00-1.49=$ Not Involved

Table 2 shows the involvement on CSR initiatives of hotel establishments. The computed composite mean score of 3.27 implies that the respondents react positively to the involvement of CSR initiatives. Generally, employees' perception and involvement of CSR are greatly affected by their hotels. The importance of CSR task significance, which is the degree to which employees believe that their job has a positive impact on the lives of others (Raub \& Blunschi, 2014).

The CSR initiatives that employees most frequently involved in is environmental effort (3.32), and both volunteering and goodwill get the same weighted mean of 3.24. The results reveal that employees of hotel establishments are proactively involved in CSR initiatives in terms of environmental effort, volunteering, and goodwill.

The respondents confirm that their hotels protect environment proactively (3.32). Environmental issue is a global topic with the growing of climate change and global warming issues in recent years. Environment relates to people's health and life closely with much research. Ahmed et al. (2020) explores the influence of corporate social responsibility (CSR) and three green triggers of environment (awareness, concern, and knowledge) on employee well-being and green behavior.

Although volunteering cost employees some time and energies, the activities allowed employees to extend their networking opportunities in an out of work, informal setting which made workplace interaction more cooperative (Supanti et al., 2015). Participating in volunteering activities offered intense experiences to staff and developed feelings of togetherness with employees from different departments, and volunteering offered fun and a chance to socialize with new friends (Peloza \& Hassay, 2006).

In summary, involvement in an environmentally and socially responsible behavior or CSR initiatives have 
always been in the line of sights of organizations all over the world. Supanti et al. (2015) found that participation of CSR is a relationship building-unifying process, employees will have fun, feel pride, develop skills, and build teamwork, and it can also enhance the employer-employee relationship. The hospitality and tourism market has been focusing on corporate social responsibility for a long time now and it has been beneficial for everyone whenever hotels engage in CSR initiatives (Ricafort, 2014). In turn, Wong and Gao (2014) noted that CSR engagement will further play a vital role in developing a corporate culture founded, in part, on employee development and harmony.

\section{Table 3}

Challenges encountered in the hotel establishments

\begin{tabular}{|c|c|c|c|}
\hline Indicators & Weighted Mean & Verbal Interpretation & Rank \\
\hline 1. Internal Challenges & 2.25 & Disagree & 1 \\
\hline 2. External Challenges & 2.19 & Disagree & 2 \\
\hline Composite Mean & 2.22 & Disagree & \\
\hline
\end{tabular}

Legend: 3.50 - 4.00 = Strongly Agree; 2.50 - 3.49 = Agree; 1.50 - 2.49 = Disagree; 1.00 - $1.49=$ Strongly Disagree

Table 3 shows challenges encountered in hotel establishments. The computed composite weighted mean score of 2.22 implies that the respondents react negatively to the challenges faced in hotel establishments. The respondents disagree with the internal and external challenges confronted in hotel establishments, although there exist some challenges in practice. Employees of hotel establishments do not participate in the management of CSR affairs, it's the matter of the management. Employees cannot deal with these internal and external challenges directly, thus they response negatively on them.

Although there are so many positive attitudes towards CSR, small and large firms alike, in developed and developing countries, report similar barriers to acting on these attitudes, including lack of time, money, support, and customer demand (Frey \& George, 2010; Garay \& Font, 2013). Some other researchers also think that the most frequently cited internal obstacle is related to a lack of money and time, and in the external sphere with the pressure of competition that obliges companies to minimize costs as these do not apply CSR measures (Miranda, Ortiz, \& Cardona, 2019). Zoweil and Montasser (2012) asserted that by using different available resources, the concept of CSR can turn threats into opportunities and achieve a competitive advantage. Spending time, money and energy on practices and involvement on CSR initiatives will cause some economic losses in short time, especially for those middle and small-sized hotels, but if they make CSR as their strategic plans and implement them continuously, they will get unexpected results for long run.

There are some determinants that decide the implementation of CSR. Miranda et al. (2019) investigated a sample of 224 hotels in Colombian Caribbean and proposed that the degree of CSR application is influenced by the size, age, category, type of contract, financial performance, and level of investment in innovation of the establishments: as well as by the sex, age, level of education, and degree of the directors' autonomy in CSR-related decision-making and their motivations and perceived obstacles.

The data on table 3 show that there's no significant differences of the responses of the respondents on the CSR practices, involvement initiatives and challenges encountered when grouped according to sex as p-values that are all higher than the alpha level. This indicates sex is not a factor which determines the CSR differences on practices, involvement and challenges encountered, and there is no notable and valid differences between male and female respondents in the CSR practices, involvement and challenges faced.

Table 4 presents the correlation between the practices on CSR, involvement on CSR initiatives and challenges encountered in the hotel establishments. It was observed that there was a strong direct correlation between the practices on CSR and involvement on CSR initiatives. In addition, the resulted p-values were less than 0.01 alpha level, thus the null hypothesis is rejected. This means that there was a significant relationship exists and implies that the better the practices, the more that the respondents involved on CSR. As shown in table 4, there is a positive correlation between practices on CSR and involvement on CSR initiatives, if hotel 
Fu, W., \& Borbon, N. M. D.

establishments practice more CSR, they will engage more in CSR initiatives. Practices on CSR will affect involvement on CSR initiatives positively.

\section{Table 4}

Relationship between CSR practices, involvement on initiatives and challenges encountered

\begin{tabular}{lccc}
\hline \multicolumn{1}{c}{ Involvement on CSR Initiatives } & F-value & $p$-value & Interpretation \\
\hline Environmental Effort & $0.895^{* *}$ & 0.000 & Highly Significant \\
Volunteering & $0.869^{* *}$ & 0.000 & Highly Significant \\
Goodwill & $0.873^{* *}$ & 0.000 & Highly Significant \\
\hline Challenges Encountered in the Hotel Establishments & & \\
\hline Internal Challenges & -0.004 & 0.934 & Not Significant \\
External Challenges & -0.043 & 0.370 & Not Significant \\
\hline Legend: Significant at $p$-value $<0.01$ & &
\end{tabular}

In modern times, the management of hotel establishments has realized the meaning and importance of CSR, and they will take various measures, including the development of CSR strategic plans, the design of CSR projects, activities such as energy conservation, water conservation, green operation and management, waste recovery and reuse, etc., which will form a strong CSR atmosphere in the hotel, so that the hotel staff perceive that the implementation of CSR is a regular obligation of the hotel and they feel it natural to participate in CSR activities.

On the other hand, hotel establishments provide enough conditions for employees to participate in CSR projects and activities, such as the necessary training for employees, and the normal payment of wages to employees when they participate in CSR activities during working hours. The management also give additional incentives to employees who often participate in CSR projects.

Shenyang Shangri-La Hotel sets a good example in implementation of CSR. It attaches importance to staff training, and new employees need to participate in induction training for three days to enter the new position. At the same time, new employees are required to participate in volunteering activities organized by the hotel within three months. Due to the nature of the hotel work, the employees of some departments will work overtime, the hotel has formulated some special policies for them, for example, providing staff lounge, work meals and corresponding logistic support, etc. Shenyang Shangri-La Hotel carries out the "Caring for Nature" project and the Earth Hour Campaign - a global energy conservation campaign launched by the Worldwide Fund for Nature (WWF). It also supports for environmental protection and commits to energy conservation and emission reduction in business. In 2018, compared to the same period in the past, Shenyang Shangri-La Hotel saved $41,920 \mathrm{kWh}$ of electricity, $16,290 \mathrm{~m}^{3}$ of water and $315,881 \mathrm{~m}^{3}$ of natural gas (Han, 2020).

Generally, involvement on CSR initiatives is based on practices on CSR. Hotel managers should invest to improve employee's awareness regarding green behavior by conducting environmental training for cultivating environmental knowledge and awareness (Ahmed et al., 2020). Therefore, hotel establishments should first train their employees awareness and knowledge related to CSR.

Su and Swanson (2019) confirm that CSR efforts can act to improve employee well-being, so undertaking social responsibility activities would appear to enhance the relationship between an organization and its employees. Furthermore, perceived CSR can also strengthen the relationship between customers and an organization (Su et al., 2016, 2017). Some other researchers suggest that CSR positively affects employee green behavior, providing additional support to recent suggestions (De Roeck \& Farooq, 2017) that green behavior in the workplace can be driven by the social settings in which employees operate. CSR has a positive influence on employees' attitudes and behaviors, and employees will participate in CSR activities if their hotels focus on CSR initiatives (Farooq et al., 2019).

The practices of hotel CSR have some impacts on residents' sentiments to community and support for 
additional tourism development. Residents' perceptions of hotels social responsibility practices contribute to residents' support for additional tourism development directly and indirectly through residents' satisfaction with their community (Gursoy et al., 2019). If residents get a good perception of the practices of hotels social responsibility, they will support hotels development and in turn they will benefit from that, i.e., priority in employment opportunities, economic development, education support, etc.

Table 5

Relationship between involvement on CSR initiatives and challenges encountered in the hotel establishments

\begin{tabular}{lccc}
\hline & r-value & $p$-value & Interpretation \\
\hline Internal Challenges & -0.001 & 0.988 & Not Significant \\
External Challenges & -0.033 & 0.495 & Not Significant \\
\hline
\end{tabular}

Legend: Significant at $p$-value $<0.05$

Table 5 shows the relationship between the involvement on CSR initiatives and challenges encountered in the hotel establishments. As seen from the table, the resulted r-values indicates an almost negligible indirect correlation, and the computed p-values were greater than 0.05 alpha level. The result indicates that the involvement on CSR initiatives was not affected by the challenges encountered.

During the implementation of CSR initiatives, hotel establishments face many problems which will attract the attention of the management, and they will take some measures to deal with them. Then the hotel will implement CSR better. However, the economic performance will affect the involvement of CSR initiatives. If the hotel does not obtain a good financial data, it will reduce its financial amount in CSR involvement. Moreover, the decision of the top management will affect the involvement of CSR initiatives. If the top management make strategic plans from long run, they will tend to engage in CSR activities and create good relationship with all stakeholders, and they will allocate more time and money to CSR activities.

Furthermore, employee's perception of the CSR of the hotel will influence the involvement of CSR initiatives, which is confirmed by Parast (2013) that company social obligation has a massive effect on employee involvement. The empirical evaluation offers help for several arguments concerning the failure of excellent control packages in promoting employee participation and involvement. The result indicates that implementation of company social obligation could have a wonderful impact at the formation of "ethical capital" of the organization through improving employee involvement. Employee involvement of CSR initiatives will increase the hotel staff morale and employees will recognize their organization and be loyal to it. They feel they are part of it and their destiny connected with the fate of the organization. In this way the hotel will obtain sustainable development.

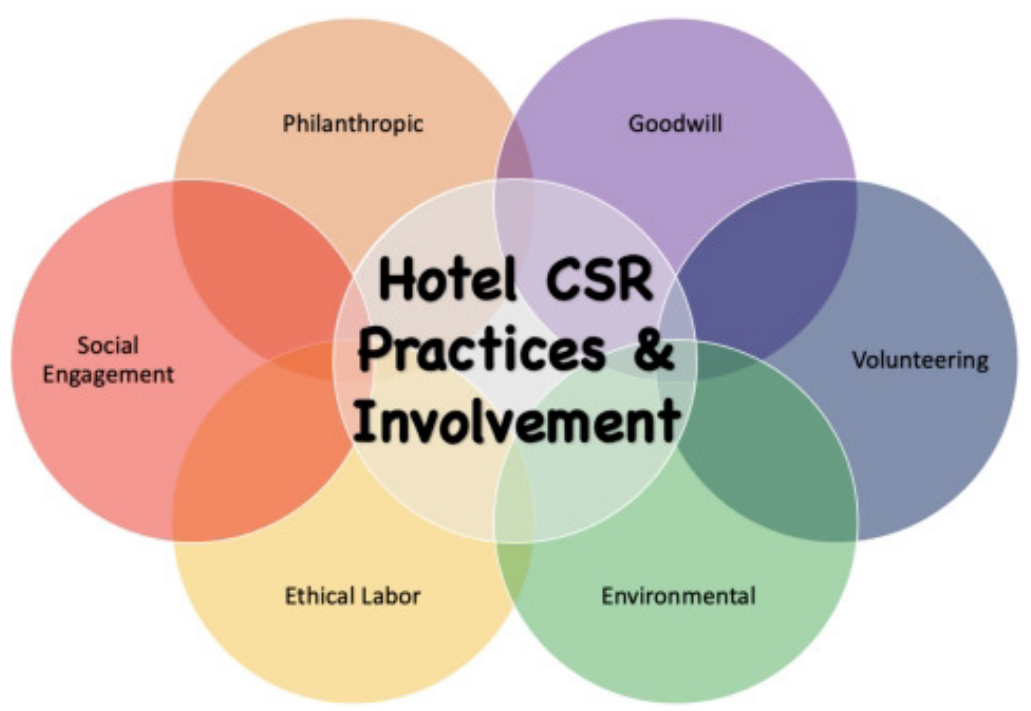

Figure 1. Framework on Hotel CSR Practices and Involvement 
Based on the result of the correlational test, it was observed that there was a strong direct correlation between the practices on CSR and involvement on CSR initiatives. This means that there was a significant relationship exists and implies that the better the practices, the more that the respondents involved on CSR. This is consistent with Parast (2013) that corporate social responsibility practices have a positive effect on employee involvement. According to Parast's study, the implementation of corporate social responsibility would have a positive effect on the formation of "moral capital" of the firm through enhancing employee involvement, and corporate social responsibility would be a much stronger driver of employee involvement. Parast argues that corporate social responsibility has an indirect effect on operational performance by improving employee involvement, and corporate social responsibility practices can be regarded as one of the soft quality practices which has a positive effect on employee involvement and participation.

Different colors have different meanings from psychological field (https://www.colorpsychology.org). As seen in the figure, environment is in green as it is the color of nature which hints at human's relationship with nature. Ethical Labor is in yellow which is associated with joy, optimism, and energy. CSR practice of hotels in ethical labor in yellow expresses that the management of the hotels made policies beneficial to the employees so that they feel satisfied and work cheerfully in the hotel in a relaxed atmosphere. This is consistent with Gurlek and Tuna (2019) that employees' work engagement could be increased with the help of CSR of their hotels. While social engagement is in red basically because red symbolizes passion, love, warmth, and energy which implies that the staff of hotels are warm-hearted and spend a lot of time participating in public benefit activities and community activities frequently. Wong and Gao (2014) confirm that the CSR-to-employee and CSR-to-customer dimensions play the most salient roles in nurturing a corporate culture that is perceived to focus on employee development, harmony, customers, and innovation. Philanthropic is in orange as it is a social color which can make people open and enhance their communication. According to the Gu, et al. (2017), hotel CSR has a significant positive impact on employee organizational identification as to their philanthropic aspect. Purple represents goodwill as it depicts influence and spiritual power. Finally, volunteering is in blue which is often associated with competence, enthusiasm, sympathetic and compassionate, spiritual pursuit, and good faith. Blue can stimulate people's mind, be helpful in concentration and mental clarity, and is linked to compassion and goodness.

The Chinese hotel establishments realized the importance of implementation of CSR since the opening and reforming. More and more managers of hotel establishments consider to make CSR as their operational strategies and many have made great achievements, which is confirmed by Plumlee et al. (2015), Tang and Zhou (2019), Khari and Sinha (2020), Jian (2019), etc. These hotel establishments engage in various CSR practices, and make their employees involve in CSR activities to attain operational performance. When they achieve their economic goal, they will invest more in CSR programs.

Hotel CSR practices are associated with the significance of corporate social responsibility which are considered the core of this framework that possibly determines the commitment of the hotel industry towards a positive implementation of corporate social responsibility (Borbon, 2020). CSR practices have become one important part of the strategic plans of most upscale hotels for sustainable and win-win development mode. Furthermore, the CSR practices of hotels will result in customer loyalty and beneficial economic performance.

\section{Conclusion and Recommendations}

Majority of the respondents are female, ages 23-38, junior college, considered as an employee for 2 years or less. The hotels often implement CSR practices in terms of environmental effort, philanthropic effort, social engagement and ethical labor. The respondents of the study affirm that their hotels are involved in CSR initiatives of hotel establishments in terms of environmental effort, volunteering, and goodwill. However, the respondents disagree that their hotels encountered significant internal and external challenges among the hotels in China. Furthermore, the study verifies that there were significant differences on internal and external challenges when grouped according to age and education degree; there were also significant differences on CSR

32 Consortia Academia Publishing (A Partner of Tourism Educators and Movers of the Philippines) 
Corporate social responsibility practices, involvement and challenges among hotels establishments in China

practices, the involvement of CSR initiatives and internal and external challenges encountered in the hotel establishments. It was also confirming that there exists a strong direct correlation between the practices on CSR and involvement on CSR initiatives. Based on the results, the researcher proposed a framework of CSR practice and involvement for hotel industry in China.

Based on the result, the following are recommended: For Hotel Owners, they may strengthen the CSR awareness among the hotel employees and the community, and they may consider having a good strategic plan of CSR, and integrate it with corporate culture, and integrate it into the daily business of hotels. For the Technical or Information Management Department of the hotels, they may disclose the information of CSR through the official website of the hotel and through publishing their CSR initiatives as well as report regularly and comprehensively to the public. For Human Resource Management of hotels, it may safeguard the basic rights and interests of their employees, protect the legitimate rights and interests of the consumers, and encourage employees and consumers to participate their CSR practices. For General Management, they may strengthen cooperation with community as well as non-governmental organizations and invite community and non-governmental organizations to fulfill CSR jointly. For the Hotel CSR Committee, they may have supervision and guidance on the practices and involvement on CSR initiatives in hotel establishments, reward hotels with better CSR performance, and punish the ones that have failed to fulfill CSR to make all hotels will bear CSR actively. For the government, it may revise and consider policy enhancement related to CSR to strengthen the regulation of hotel CSR. For the future researchers, they may conduct related studies on CSR focusing on the CSR practices in the time of pandemic and its impact on the corporate image of the hotel.

\section{References}

Ahmadi, A., \& Bouri, A. (2017). The relationship between financial attributes, environmental performance and environmental disclosure. Management of Environmental Quality, 28(4), 490-506. https://doi.org/10.1108/MEQ-07-2015-0132

Ahmed, M., Zehou, S., Raza, S. A., Qureshi, M. A., \& Yousufi, S. Q. (2020). Impact of CSR and environmental triggers on employee green behavior: The mediating effect of employee well-being. Corporate Social Responsibility and Environmental Management, 27(5), 2225-2239. https://doi.org/10.1002/csr.1960

Borbon, N. (2020). Corporate social responsibility practices among DOT accredited hotel establishments in Calabarzon region. Journal on Tourism \& Sustainability, 4(1), 16-26.

Borbon, N. M. D. (2019). A proposed framework of commitment for hotel industry in CALABARZON Region, Philippines. Asia Pacific Journal of Education, Arts and Sciences, 6(2).

Chen, L. F. (2019). Hotel chain affiliation as an environmental performance strategy for luxury hotels. International Journal of Hospitality Management, 77(1), 1-6.

De Roeck, K., \& Farooq, O. (2017). Corporate social responsibility and ethical leadership: Investigating their interactive effect on employees' socially responsible behavior. Journal of Business Ethics, 151(4), 923-939. https://doi.org/10.1007/s10551-017-3656-6

Farooq, M., Farooq, O., \& Cheffi, W. (2019). How do employees respond to the CSR initiatives of their organizations: Empirical evidence from developing countries. Sustainability, 11(9), 2646. https://doi.org/10.3390/su11092646

Frey, N., \& George, R. (2010). Responsible tourism management: The missing link between business owners' attitudes and behaviour in the Cape Town tourism industry. Tourism Management, 31, 621-628.

Garay, L., \& Font, X. (2013). Corporate social responsibility in tourism small and medium enterprises. Evidence from Europe and Latin America. Tourism Management Perspectives, 7, 38-46.

Gu, H. M., Jia, H., \& Zhao, Y. X. (2017). A study on the influence of corporate social responsibility on hotel employee's turnover tendency: The intermediation of organizational identification. Human resources Development of China, 4, 47-53.

Gürlek, M., \& Tuna, M. (2019). Corporate social responsibility and work engagement: Evidence from the hotel industry. Tourism Management Perspectives, 31(7), 195-208. https://doi.org/10.1016/j.tmp.2019.05.004 
Gursoy, D., Boğan, E., Dedeoğlu, B. B., \& Çalışkan, C. (2019). Residents' perceptions of hotels' corporate social responsibility initiatives and its impact on residents' sentiments to community and support for additional tourism development. Journal of Hospitality and Tourism Management, 39(6), 117-128. https://doi.org/10.1016/j.jhtm.2019.03.005

Han, C. T. (2020). A study on the evaluation system of corporate social responsibility of hotels under ISO26000 framework _ Taking Shangri-La Hotel in Shenyang as an example (Master's dissertation). Shenyang Normal University, China.

Jian, Y. H. (2019) Study on the impact of corporate environmental responsibility on corporate financial performance in hospitality industry (Master's thesis). Northeast University of Finance and Economics, China.

Khari, C., \& Sinha, S. (2020). Organizational spirituality and employee volunteering: A study of mediating variables. Vision: The Journal of Business Perspective, 24(4), 460-470.

Li, L. (2012). The green hotel management under the perspective of social responsibility. WTO Economic Tribune, 9, 66-68.

Miranda, D. D. P., Ortiz, J. A., \& Cardona, J. R. (2019). Determinants of CSR application in the hotel industry of the Colombian Caribbean. Sustainability, 11, 5045.

Ouyang, Z.., Wei, W., \& Chi C. G. (2019). Environment management in the hotel industry: Does institutional environment matter? International Journal of Hospitality Management, 77(1), 353-364.

Parast, M. M. (2013). Quality citizenship, employee involvement, and operational performance: An empirical investigation. International Journal of Production Research, 51(10), 2805-2820.

Peloza, J., \& Hassay, D. N. (2006). Intra-organizational volunteerism: Good soldiers, good deeds and good politics. Journal of Business Ethics, 64(4), 357-379. https://doi.org/10.1007/s10551-005-5496-Z

Plumlee M., Brown D., Hayes R. M., \& Marshall R. S. (2015). Voluntary environmental disclosure quality and firm value: Further evidence. Journal of Accounting and Public Policy, 34(4), 336-361. https://doi.org/10.1016/j.jaccpubpol.2015.04.004

Raub, S., \& Blunschi, S. (2014). The power of meaningful work: How awareness of CSR initiatives fosters task significance and positive work outcomes in service employees. Cornell Hospitality Quarterly, 55, 10-18. https://doi.org/10.1177/1938965513498300

Ricafort, K. G. F. (2014) A study on the impact of corporate social responsibility on workforce satisfaction: Analysis of Manila's 5-star hotels (Master's dissertation). Harbin Institute of Technology, China.

Su, L. J., \& Swanson, S. R. (2019). Perceived corporate social responsibility's impact on the well-being and supportive green behaviors of hotel employees: The mediating role of the employee-corporate relationship. Tourism Management, 72(6),437-450. https://doi.org/10.1016/j.tourman.2019.01.009

Su, L. J., Swanson, R. S., Hsu, M., \& Chen, X. (2017). How does perceived corporate social responsibility contribute to green consumer behavior of Chinese tourists: A hotel context. International Journal of Contemporary Hospitality Management, 29(12), 3157-3176. https://doi.org/10.1108/IJCHM-10-2015-0580

Su, L. J., Swanson, S. R., \& Chen, X. (2016). Social responsibility and reputation influences on the intentions of Chinese Huitang village tourists. International Journal of Contemporary Hospitality Management, 28(8), 1750-1771. https://doi.org/10.1108/IJCHM-06-2014-0305

Supanti, D., Butcher, K., \& Fredline, L. (2015). Enhancing the employer-employee relationship through corporate social responsibility (CSR) engagement. International Journal of Contemporary Hospitality Management, 27(7), 1479-1498. https://doi.org/10.1108/IJCHM-07-2014-0319

Tan S. H., Habibullah M. S., Tan S. K., \& Choon S. W. (2017). The impact of the dimensions of environmental performance on firm performance in travel and tourism industry. Journal of Environmental Management, 203(12), 603-611. https://doi.org/10.1016/j.jenvman.2017.02.029

Tang, H., \& Zhou, W. (2019). Study on the evaluation system of hotel social responsibility based on consumer perspective. Economic Research Guide, 30, 149-152.

Tang. S. H. (2014) Research on the construction of hotel environmental responsibility report system based on content analysis (Master's thesis). South China University of Technology, China.

34 Consortia Academia Publishing (A Partner of Tourism Educators and Movers of the Philippines) 
Vizconde, A. M. L. (2019). Sustainable community-based development framework for golf courses and country clubs in the Philippines (Doctorial dissertation). Lyceum of the Philippines University-Batangas.

Wong, I. A., \& Gao, J. H. (2014). Exploring the direct and indirect effects of CSR on organizational commitment: The mediating role of corporate culture. International Journal of Contemporary Hospitality Management, 26(4), 500-525. https://doi.org/10.1108/IJCHM-05-2013-0225

Yao, L. (2012). A study on hotel's behavioral intention to social responsibility based on planning behavior theory (Master's dissertation). Shanghai Normal University, China.

Zhao, D. L. (2018). Research and model of hotel corporate social responsibility in environment (Master's dissertation). Northeast University of Finance and Economics, China.

Zoweil, R. Y., \& Montasser, M. G. (2012). Achieving corporate social responsibility based on human resources dimension: a case study approach, Porto Marina resort in Egypt. Sustainable Tourism, 5, 69-79.

https://doi.org/10.2495/ST120061 
Fu, W., \& Borbon, N. M. D.

36 Consortia Academia Publishing (A Partner of Tourism Educators and Movers of the Philippines) 